\title{
Evaluation of the Performance of Females as Light Infantry Soldiers
}

\author{
Aharon S. Finestone, ${ }^{1,2}$ Charles Milgrom, ${ }^{3}$ Ran Yanovich, ${ }^{2}$ Rachel Evans, ${ }^{4}$ \\ Naama Constantini, ${ }^{3}$ and Daniel S. Moran ${ }^{2,5}$ \\ ${ }^{1}$ Department of Orthopaedic Surgery, Assaf Harofeh Medical Center, Zerifin \& Sackler School of Medicine, \\ Tel Aviv University, 69978 Tel Aviv, Israel \\ ${ }^{2}$ Israel Defense Forces Institute of Military Physiology and Heller Institute of Medical Research, Haim Sheba Medical Center, \\ Military P.O. Box 02149, 52621 Ramat Gan, Israel \\ ${ }^{3}$ Hebrew University Medical School, Ein Kerem, 91120 Jerusalem, Israel \\ ${ }^{4}$ Bone Health Research Program, U.S. Army Research Institute of Environmental Medicine, Military Performance Division, \\ Natick, MA 01760, USA \\ ${ }^{5}$ Ariel University, 40700 Ariel, Israel \\ Correspondence should be addressed to Charles Milgrom; charlesm@ekmd.huji.ac.il
}

Received 24 April 2014; Revised 2 August 2014; Accepted 5 August 2014; Published 18 August 2014

Academic Editor: Laura Guidetti

Copyright (C) 2014 Aharon S. Finestone et al. This is an open access article distributed under the Creative Commons Attribution License, which permits unrestricted use, distribution, and reproduction in any medium, provided the original work is properly cited.

\begin{abstract}
A few countries permit women to serve in combat roles, but their long term performance in these positions has not been reported. The incidences of overuse injuries and attrition of 85 male and 235 female recruits in a light infantry brigade was followed in a threeyear prospective study. Females were shorter $(162 \mathrm{~cm}$, CI 161-163 cm) than males $(174 \mathrm{~cm}, \mathrm{CI} 173-176)$, had more body fat (18.9 kg, CI $18.2-19.6 \mathrm{~kg}$ ) than males $(12.6 \mathrm{~kg}, 11.3-13.8 \mathrm{~kg})$, had lower $\dot{\mathrm{V}} \mathrm{O}_{2} \max \left(36.8 \mathrm{~mL} \cdot \mathrm{min}^{-1} \cdot \mathrm{kg}^{-1}\right.$, CI $\left.35.8-37.78 \mathrm{~mL} \cdot \mathrm{min}^{-1} \cdot \mathrm{kg}^{-1}\right) \mathrm{than} \mathrm{males}^{-1}$ $\left(50.48 \mathrm{~mL} \cdot \mathrm{min}^{-1} \cdot \mathrm{kg}^{-1}\right.$, CI 48.4 to $\left.52.48 \mathrm{~mL} \cdot \mathrm{min}^{-1} \cdot \mathrm{kg}^{-1}\right)$, had more stress fractures $(21.0 \%, 95 \%$ CI $16.2-26.5 \%)$ than males $(2.3 \%$, CI $0.3-8.2 \%)$, and had more anterior knee pain (41.2\%, CI 34.9-47.7\%) than males (24.7\%, CI 16.0-35.2\%). Three-year attrition was $28 \%$ CI $22-34 \%$ for females and $37 \%$ CI $26-48 \%$ for males. The females in this study successfully served as light infantry soldiers. Their lower fitness and high incidence of overuse injuries might impede service as regular infantry soldiers.
\end{abstract}

\section{Introduction}

Opposition to women serving in military combat positions has come both from within the armed forces and from groups in the general society. The arguments are many, including the position that women are not able to adequately perform combat duties. Beginning in the 1970s, Canada, the USA, Taiwan, Israel, New Zealand, and a few European nations gradually began to allow women to serve in more active combat roles. Of these countries, only Israel has compulsory military service for women. The performance of women in these active combat roles has not been well documented and publicized. Military studies have found that female stress fracture risk and overuse injury risk are greater than those of males doing the same training $[1,2]$. Other studies have focused on identifying gender specific risk factors for overuse injuries in the military [3-5].

Measurement of the professional performance of combat soldiers is multifactorial. Dropout from combat units can be considerable. It can be secondary to acute injuries, overuse injuries, lack of motivation, sociological reasons, or psychological factors. Several studies have focused on the attrition of females in the armed forces [6-10]. During U.S Army Basic Combat Training, the medical discharge rate for males is 3.3 percent as compared to 8.7 percent for females [11]. At one year, the attrition rate among female U.S. Marine Corp recruits was reported to be 17 percent [6]. The overall attrition rate of female soldiers in the U.S. Marine Corp has been reported to be 1.6 times higher than that of males [7]. 
In 1995, the Israel Supreme Court ruled that the Israel Ministry of Defense policy of not allowing women entrance into the Israel Air Force pilot's course was solely based on gender and, therefore, constituted unlawful discrimination. This decision initiated radical changes in the combat active service opportunities for women in the Israel Defense Forces (IDF). Today, women serve in combat roles in many IDF units including the light infantry brigade Karakal, antiaircraft units, the Home Front Command, and the Border Police, in the Navy and in the Air Force.

In view of the controversy about females serving in combat positions, we undertook a study to compare the long term performance of females and males in the mixed gender light infantry brigade of the Israeli Defense Forces. We report the results of a prospective study of the incidences of their overuse injuries, attrition, and completion of officers' course over the course of their three years of compulsory service.

\section{Methods}

2.1. Subjects. Mandatory military service in Israel is three years for males and two years for females. Before induction, future recruits undergo a battery of tests which rate their psychotechnical skills (maximum score 90) and rank their quality as potential military recruits (maximum score 56). They also are given a health profile which determines whether their health status allows them to serve as combat soldiers or not. Males are assigned to service in Karakal, a mixed gender light infantry brigade from the general induction pool of combat eligible males, but females, in addition to having combat eligible health profiles, need to request and volunteer for the unit, agreeing to extend their service from two to three years. The study subjects are female and male Karakal recruits from three consecutive inductions (September 2004 through July 2005). Karakal basic training is 14 weeks. Completion of this training qualifies recruits as light infantry soldiers.

The study was approved by the IRB's of the Israel Defense Forces Medical Corps, the Sheba Medical Center, and the U.S. Army Research Institute of Environmental Medicine at Natick, MA. All the participants signed informed consent for participation in the study.

2.2. Measurements. All subjects in the study had baseline measurements during the first week after their military induction and had subsequent follow-up measurements at the end of basic training 14 weeks later. Anthropometric measurements were made of height (nearest $\mathrm{cm}$ ), weight (after voiding), external rotation of the hip at 90 degrees of flexion, tibia length (medial knee joint line to the most medially prominent point of the medial malleolus), and body fat percentage (calculated from four skinfold thickness measurements over right biceps, triceps, scapula, and iliac crest, Lange skinfold calipers (Beta Technology, Santa Cruz, CA)) [11-13]. Maximum quadriceps force was measured in $\mathrm{kgF}$, using a quadriceps extension machine. $\dot{\mathrm{V}}_{2} \max$ $\left(\mathrm{mL} \cdot \mathrm{min}^{-1} \cdot \mathrm{kg}^{-1}\right)$ was measured using the modified Bruce treadmill protocol, using peak oxygen uptake (SensorMedics Co., CA, USA) [14-16]. According to the protocol, exercise was increased incrementally until the $\dot{\mathrm{VO}}{ }_{2}$ reached a plateau and was not increase further in spite of increased effort.

Recruits' pre- and posttraining physical fitness was assessed in the field with the standard IDF fitness test (originally developed by Oded Bar-Or and since modified) administered by the unit officers during the first two weeks of basic training and subsequently during weeks 14-15 after induction. The test includes a $2 \mathrm{~km}$ run (minimum time in minutes) and the maximum number of pushups and situps performed consecutively without rest [15].

Questionnaires were administered relating to preinduction injury (including stress fractures (SF), ankle sprains, and back and knee pain), preinduction sports activity [17], smoking history, motivation, cohesion, and stress [18]. This study also used the Bem Sex Role Inventory (BSRI) [19] to calculate the participants' socially defined degrees of masculinity and femininity. Each participant's scores were dichotomized for both masculinity and femininity by their medians, which further allocated them into the four categories of (a) under the median in both scores (nonsex type), (b) over the median in both scores (androgynous type), (c) below the masculine and over the feminine score (feminine type), and (d) over the masculine and under the feminine score (masculine type). The Lazarus and Folkman Ways of Coping questionnaire [20] was used to assess the participants' coping styles (respondents' cognitive and behavioral efforts when confronting stress: scores for distance, problem solving, acceptance, and growth). The Kobasa Questionnaire [21, 22] was used to measure hardiness, subdivided into three subscales measuring commitment, control, and challenge. Burnout was measured using the Shirom-Melamed Burnout Questionnaire [23]. Self-efficacy was assessed using a specially designed nine-item questionnaire. A six-item stress questionnaire included questions regarding perceived stress, having tools to deal with stress, and the recruits' opinion of whether he/she expected to fulfill three years of service.

Female and male combatants were examined in the field by a team of orthopedic surgeons every 2 to 3 weeks during 16 weeks of basic training and were screened for overuse injuries. Suspected stress fractures were diagnosed by radiography and/or bone scan and were treated according to the IDF protocol $[24,25]$. All data were recorded directly into a laptop using an Access database (Microsoft Corp., Redmond, WA). Injuries that occurred after completion of basic training were collected manually from the IDF Computerized Patient Record (a centralized medical file) and inserted directly into the Access database. Data on completion of stages and courses in military service and hospitalizations were taken from the central IDF manpower database and subsequently entered into the Access database.

2.3. Statistical Analysis. Data analysis was performed on SAS (SAS Institute Inc., Cary North Carolina, USA). Univariate analysis on nominal variables was performed using chisquare (or Fisher's exact test when expected cell count $<5$ ) and on continuous variables using Student's $t$-test or ANOVA (analysis of variance). For changes over the training period, paired $t$-tests and repeated measures ANOVA using GLM 
TABLE 1: Anthropometric data (mean \pm SD) for female and male Karakal recruits who completed basic training before and after 14 weeks of basic training course.

\begin{tabular}{|c|c|c|c|}
\hline & Females $(n=227)$ & Males $(n=78)$ & $P$ value \\
\hline Age (year) & $19.1 \pm 0.6$ & $19.3 \pm 1.2$ & NS \\
\hline Height (cm) & $162 \pm 6$ & $175 \pm 7$ & $<0.0001$ \\
\hline $\mathrm{BMI}\left(\mathrm{kg} \cdot \mathrm{m}^{-2}\right)$ & $23.1 \pm 3.4$ & $22.8 \pm 4.0$ & NS \\
\hline Quadriceps force (kgF) & $82 \pm 24$ & $124 \pm 29$ & $<0.0001$ \\
\hline Weight (at induction, kg) & $60.7 \pm 9.9$ & $69.8 \pm 13.1$ & $<0.0001$ \\
\hline Weight (at week 14, kg) & $61.5 \pm 9.6$ & $68.9 \pm 11.7$ & $<0.0001$ \\
\hline$\Delta$ Weight $(\mathrm{kg})$ & $0.8 \pm 2.6^{* * *}$ & $-0.1 \pm 5.0^{\varsigma}$ & NS \\
\hline Fat \% (at induction) & $30.7 \pm 4.6$ & $17.3 \pm 4.8$ & $<0.0001$ \\
\hline Fat \% (at week 14) & $29.6 \pm 4.4$ & $15.9 \pm 4.0$ & $<0.0001$ \\
\hline$\Delta$ Fat $\%$ & $-1.2 \pm 2.9^{* * *}$ & $-1.3 \pm 2.2^{* * *}$ & NS \\
\hline Fat mass (at induction, $\mathrm{kg}$ ) & $18.9 \pm 5.5$ & $12.6 \pm 5.7$ & $<0.0001$ \\
\hline Fat mass (at week 14, kg) & $18.5 \pm 5.2$ & $11.4 \pm 4.4$ & $<0.0001$ \\
\hline$\Delta$ Fat mass $(\mathrm{kg})$ & $0.5 \pm 2.3^{* *}$ & $-0.1 \pm 2.3^{* *}$ & NS \\
\hline Lean body mass (at induction, $\mathrm{Kg}$ ) & $41.7 \pm 5.4$ & $57.2 \pm 8.1$ & $<0.0001$ \\
\hline Lean body mass (at week 14, kg) & $43.0 \pm 5.3$ & $57.6 \pm 7.9$ & $<0.0001$ \\
\hline$\Delta$ Lean body mass $(\mathrm{kg})$ & $1.3 \pm 1.7^{* * *}$ & $1.1 \pm 3.6^{*}$ & NS \\
\hline$\dot{\mathrm{V}} \mathrm{o}_{2} \max \left(\right.$ at induction, $\mathrm{mL} \cdot \mathrm{kg}^{-1} \cdot \mathrm{min}^{-1}$ ) & $36.8 \pm 6.4$ & $50.4 \pm 7.8$ & $<0.0001$ \\
\hline$\dot{\mathrm{V}} \mathrm{O}_{2} \max \left(\right.$ at week $\left.14, \mathrm{~mL} \cdot \mathrm{kg}^{-1} \cdot \mathrm{min}^{-1}\right)$ & $39.8 \pm 5.9$ & $52.4 \pm 7.0$ & $<0.0001$ \\
\hline$\Delta \dot{\mathrm{V}} \mathrm{o}_{2} \max \left(\mathrm{mL} \cdot \mathrm{kg}^{-1} \cdot \mathrm{min}^{-1}\right)$ & $3.0 \pm 7.6^{* * *}$ & $2.0 \pm 7.6^{\S}$ & NS \\
\hline
\end{tabular}

$P$ values for deltas: ${ }^{*} P=0.05,{ }^{* *} P<0.001,{ }^{* * *} P<0.0001$, and ${ }^{\S} \mathrm{NS}$.

TABLE 2: Before and after 14-week basic training female and male fitness test (mean $\pm \mathrm{SD}$ ).

\begin{tabular}{cccc}
\hline & Females $(n=197)$ & Males $(n=60)$ & $P$ value \\
\hline 2 km run at induction (sec) & $739 \pm 115$ & $570 \pm 101$ & $<0.0001$ \\
2 km run at 14 weeks (sec) & $667 \pm 76.0$ & $533 \pm 80.4$ & $<0.0001$ \\
$\Delta$ Run time (sec) & $-72 \pm 78^{* * *}$ & $-37 \pm 68^{* *}$ & $<1 \pm 18$ \\
Pushups at induction & $40 \pm 11$ & $67 \pm 14$ & $<0.002$ \\
Pushups at 14 weeks & $49 \pm 7$ & $26 \pm 14^{* * *}$ & $<0.0001$ \\
$\Delta$ Pushups & $9 \pm 13^{* * *}$ & $64 \pm 26$ & NS \\
Situps at induction & $66 \pm 27$ & $86 \pm 10$ & NS \\
Situps at 14 weeks & $84 \pm 12$ & $22 \pm 23^{* * *}$ & NS \\
$\Delta$ Situps & $17 \pm 28^{* * *}$ & &
\end{tabular}

$P$ values for deltas: ${ }^{* *} P<0.01,{ }^{* * *} P<0.0001$.

(general linear models) were used. Hospital admissions were counted if they were for more than 24 hours. Attrition rates were compared at 18 months and at three years. Survival analysis for combatants in their designated service was performed using PROC LIFETEST (a standard SAS routine). Data were censored at 18 months/three years. Attrition date was set at the earlier of two dates, the subject leaving the unit or receiving a medical profile that made leaving obligatory. Variables, possibly related to stress fracture and attrition in female combatants, were tested using Student's $t$-test, and relevant variables were tested in multivariate analysis using stepwise logistic regression. Significant difference was at $P<0.05$.

\section{Results}

238 females (94\% of those eligible) and 85 males (91\% of those eligible) volunteered to participate in the study.
227 out of the 238 females (95\%) and 78 out of the 85 males (92\%) completed basic training. The baseline anthropometric data for those recruits who completed basic training is presented in Table 1 . Females were shorter $(162 \mathrm{~cm}$, CI $161-163 \mathrm{~cm})$ than males $(174 \mathrm{~cm}$, CI $173-176)$, had more body fat $(18.9 \mathrm{~kg}$, CI $18.2-19.6 \mathrm{~kg})$ than males $(12.6 \mathrm{~kg}, 11.3-13.8 \mathrm{~kg})$, had lower quadriceps strength $(82 \mathrm{kgF}$, CI 78 to $86 \mathrm{kgF}$ ) than males $(124 \mathrm{kgF}, 117$ to $131 \mathrm{kgF})$, and had lower $\dot{\mathrm{VO}_{2}} \max \left(36.8 \mathrm{~mL} \cdot \mathrm{min}^{-1} \cdot \mathrm{kg}^{-1}\right.$, CI $35.8-$ $\left.37.78 \mathrm{~mL} \cdot \mathrm{min}^{-1} \cdot \mathrm{kg}^{-1}\right)$ than males $\left(50.48 \mathrm{~mL} \cdot \mathrm{min}^{-1} \cdot \mathrm{kg}^{-1}\right.$, CI 48.4 to $\left.52.48 \mathrm{~mL} \cdot \mathrm{min}^{-1} \cdot \mathrm{kg}^{-1}\right)$. The results of their physical fitness tests are presented in Table 2.

On induction, $38 \%$ of the females and $49 \%$ of males reported smoking $(P=0.08)$. Sixteen percent of females and $23 \%$ of males reported that they smoked at least half a pack for more than a year $(P=0.2)$. There was no statistically 
TABLE 3: Stress fracture (SF) and other overuse injuries of female and male soldiers (\%) during 36 months of military service.

\begin{tabular}{lccc}
\hline & $\begin{array}{c}\text { Females } \\
(N=238)\end{array}$ & $\begin{array}{c}\text { Males } \\
(N=85)\end{array}$ & $P$ \\
\hline Femoral SF & $17(7.1)$ & $1(1.2)$ & $<0.04$ \\
Tibia SF & $29(12.2)$ & $1(1.2)$ & $<0.003$ \\
Fibular SF & $3(1.3)$ & 0 & NS \\
Metatarsal SF & $10(4.2)$ & 0 & $<0.05$ \\
Other SF & $4(1.7)$ & 0 & NS \\
Total SF & $50(21.0)$ & $2(2.3)$ & $<0.0001$ \\
Ant knee pain & $98(41.2)$ & $21(24.7)$ & $<0.007$ \\
Back pain & $88(37.0)$ & $36(42.3)$ & NS \\
Ankle sprain & $46(19.3)$ & $16(18.8)$ & NS \\
Achilles & $7(2.9)$ & $3(3.5)$ & NS \\
tendinitis & & &
\end{tabular}

significant difference in the preinduction sports participation between females (48\%) and males (52\%).

The mean psychotechnical index of females was $58.2 \pm$ 16.8 and that of males was $57.6 \pm 19.7(P=0.8)$. The quality measurement for females was $51.7 \pm 2.8$ and for males $51.2 \pm$ $3.72(P=0.2)$.

During the 14 weeks of basic training, both groups gained weight but the gain was not significant for males. Female soldiers gained $1.3 \pm 1.7 \mathrm{~kg}$ of lean body mass. On repeated measures analysis, group and phase differences were statistically significantly, with no interaction for weight and $\mathrm{V}_{2}$ max and interaction for fat percent, fat mass, and lean body mass. The Pearson Correlation Coefficient between induction $\mathrm{VO}_{2}$ max and the $2 \mathrm{~km}$ running time was 0.479 for females and 0.372 for males.

The incidence of stress fracture diagnosed during the 36 -month period was higher for females $(21.0 \%, 95 \%$ CI $16.2-26.5 \%)$ than for males (2.3\%, CI $0.3-8.2 \%)$ (Table 3 ). The date of onset of pain for those diagnosed with stress fractures is presented in Figure 1. The females had more anterior knee pain (41.2\%, CI 34.9-47.7\%) than males (24.7\%, CI $16.0-35.2 \%)$. On univariate analysis, the only variables that were found to have a statistically significant relationship to the incidence of stress fractures among females were the lower BMI $\left(22.0 \mathrm{~kg} \cdot \mathrm{m}^{-2}\right.$ versus $\left.23.3 \mathrm{~kg} \cdot \mathrm{m}^{-2}, P=0.02\right)$ and less body fat $(16.9 \mathrm{~kg}$ versus $18.7 \mathrm{~kg}, P=0.04)$ among those with stress fractures as compared with those without stress fractures. Neither of these factors was significant on multivariate analysis.

At 18 months, $76 \%$ of females and $68 \%$ of males were still serving as combat soldiers. Three-year attrition was $(28 \%$, CI $22-34 \%)$ for females and (37\% CI $26-48 \%)$ for males. The main reasons for not completing service were nonmedical (Table 4). Medical reasons for attrition are detailed in Table 5. Survival analysis demonstrated that female soldiers survived $28.2 \pm 0.8$ months (mean \pm SE) and males $19.4 \pm 0.9$ months. Females who dropped out had a statistical trend of weaker quadriceps force than their counterparts who remained in the unit $(79 \mathrm{kgF}$ versus $87 \mathrm{kgF}, P=0.08)$ and a slower
TABLE 4: Summary of the formal reasons of attrition. Medical and psychological issues needed professional diagnosis and profile change through a formal medical board. Administrative issues refer to all other reasons for attrition including the soldier's request, lack of motivation, lack of physical, social, or mental competency, and family issues preventing engaging in training or service.

\begin{tabular}{lccc}
\hline $\begin{array}{l}\text { Reasons for } \\
\text { attrition }\end{array}$ & $\begin{array}{c}\text { Females } \\
(N=238)\end{array}$ & $\begin{array}{c}\text { Males } \\
(N=85)\end{array}$ & $P$ value \\
\hline $\begin{array}{l}\text { Medical issues } \\
\begin{array}{l}\text { Psychological } \\
\text { issues }\end{array}\end{array}$ & $18(7.6 \%)$ & $6(7.1 \%)$ & NS \\
$\begin{array}{l}\text { Administrative } \\
\text { issue }\end{array}$ & $35(14.7 \%)$ & $9(10.6 \%)$ & NS \\
\hline $\begin{array}{l}\text { Total attrition } \\
\begin{array}{l}\text { Completed } \\
\text { designated service }\end{array}\end{array}$ & $67(28.2 \%)$ & $31(36.5 \%)$ & NS \\
\hline
\end{tabular}
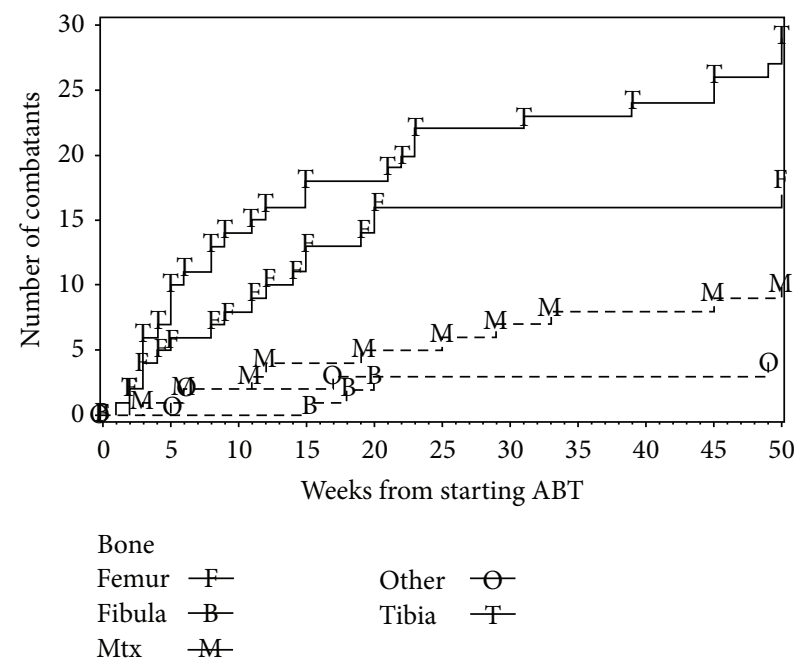

FIGURE 1: Onset of stress fractures (in weeks from starting basic training) for female soldiers by bone. Fractures after 50 weeks were marked at 50 .

running time (12:44 versus $12: 15, P=0.06)$ but no difference in $\dot{\mathrm{VO}_{2}}$ max. Attrition was significantly related to having back pain during training. Females with backache were significantly more likely to drop out (37\%) than males (23\%), $P=0.01$. Rates of nongynecological hospital admissions were $12 \%$ for females and $16 \%$ for males during the 36-month period.

Attrition was associated with a significantly higher response to the question "Do you think the assignment you are undertaking will be stressful?" (4.1 versus 3.3 on a scale of 1 to $5, P<0.0001)$. Attrition was also associated will significantly lower response to "I am likely to complete 3 years in this assignment" ( 4.0 versus 4.4 on a scale of 1 to $5, P=0.003)$. Of the factors derived from the various questionnaires, attrition was significantly associated with an androgen personality trait (respondents with high scores on both masculine and feminine characteristics: androgen $43 \%$, not androgen $22 \%$, and relative risk 2.0 confidence interval 
TABLE 5: Summary of the formal medical reasons for attrition.

\begin{tabular}{lccc}
\hline $\begin{array}{l}\text { Reasons for } \\
\text { attrition }\end{array}$ & $\begin{array}{c}\text { Females } \\
(N=238)\end{array}$ & $\begin{array}{c}\text { Males } \\
(N=85)\end{array}$ & Total \\
\hline Back pain & 3 & 1 & 4 \\
$\begin{array}{l}\text { Knee pain } \\
\text { Irritable bowel }\end{array}$ & 3 & 1 & 4 \\
$\begin{array}{l}\text { syndrome } \\
\text { Pes cavus/Pes } \\
\text { planus }\end{array}$ & 2 & & 2 \\
$\begin{array}{l}\text { Skin disease } \\
\text { Asthma }\end{array}$ & 2 & 1 & 2 \\
$\begin{array}{l}\text { Anaemia } \\
\text { Ankle sprain }\end{array}$ & 1 & 1 & 2 \\
$\begin{array}{l}\text { Stress fracture } \\
\text { (nondisplaced) }\end{array}$ & 1 & & 2 \\
$\begin{array}{l}\text { Fracture (upper } \\
\text { extremity) }\end{array}$ & 1 & & 2 \\
$\begin{array}{l}\text { Fracture of spine } \\
\text { Kidney disease }\end{array}$ & 1 & & 1 \\
$\begin{array}{l}\text { Ticks } \\
\text { (neurological) }\end{array}$ & & 1 & 1 \\
\hline \begin{tabular}{l} 
Total \\
\hline
\end{tabular} & 18 & & 1 \\
\hline
\end{tabular}

1.2 to 3.1). On multivariate analysis, all above factors entered the model (in decreasing order of statistical significance: expected stress, negative anticipation of assignment completion, androgen trait, and back pain during service).

Five percent of females and one percent of males in the study completed officer's course and became officers. Sixty percent of females and males did reserve army service after completing their three years of mandatory service.

\section{Discussion}

Female soldiers of Karakal had a high rate of attrition, with only seventy two percent remaining as combat soldiers throughout their three years of military service. This retention rate, however, was in fact higher than that of male Karakal soldiers. From this standpoint, the program of female service in the mixed gender light infantry unit Karakal can be considered a success.

From a physical standpoint, the females in Karakal, when compared to the males, began their training at a physiological disadvantage. Their $\dot{\mathrm{VO}}_{2} \max$ measurements and time for a $2 \mathrm{~km}$ run were poorer than those of the males. $\dot{\mathrm{VO}}_{2} \max$ in itself is known to be a poor prediction of run performance. The velocity and duration at which subjects can operate at their $\dot{\mathrm{VO}}_{2}$ max provide better indications of performance. Females were able to do less situps and pushups than males at the beginning of basic training. This deficit remained even after 14 weeks of basic training. The females were also shorter and weighed less than the males. This put them at a disadvantage to the males because they used the same equipment and carried the same base loads while training [26]. The females sustained a 21-percent incidence of stress fractures versus a 2-percent incidence for the males. With the exception of stress fractures and anterior knee pain, which were higher in females, there was no difference in the incidence of the other types of overuse injuries between females and males. In spite of the high incidence of stress fractures and the physical and physiological differences between the women and men of Karakal, their attrition rates because of medical reasons were the same.

The attrition rate for males in Karakal was higher than that of the females principally because of drop out for psychological reasons. The psychological variables specifically measured in this study do not fully explain this large difference. One reason may be because the females in Karakal volunteered specifically for service in Karakal while the males were assigned to the unit from the general pool of males designated for combat service. For females, Karakal is one of the most prestigious army combat units in which they could serve, but, for males, it is one of the least prestigious combat units in which they can serve. The IDF has several systems for evaluating recruits prior to induction. There was no statistically significant difference in the preinduction psychotechnical scores and quality scores between the women and men of Karakal. The psychotechnical scores of the Karakal soldiers were lower than those of regular IDF infantry soldiers. Both the female and male Karakal attrition rates were much higher those of regular IDF infantry soldiers, who have more arduous training. Neither of the psychotechnical nor quality scores were predictors of attrition in this study.

Discharge rates among female American Marine Corp recruits, based on 1999-2000 data, have been reported to be 11.2 percent in basic training, with a one year attrition rate of 17.1 percent [7]. This compares to the 24-percent attrition rate for the females of Karakal at 18 months. Unlike the female Marines, most of the Karakal females who left their unit continued to serve but in noncombat positions. In another American Marine Corp study, based on data from 1997, the female discharge rate was 18.2 percent and the male rate was 11.9 percent during 63 days of Marine Corp basic training at Parris Island [6].

In the current study, $5 \%$ percent of the females and one percent of the males completed officer's course and became officers. The IDF is different from the American Army in the fact that officers begin as regular soldiers and therefore data cannot be compared. Those who are identified during their training as being good officer candidates are offered the chance to take an officer's course. Being an officer also requires the soldier to serve for an additional year and not all candidates are willing to do so. About $10 \%$ of soldiers in IDF regular infantry units complete officer's course. Since the IDF relies heavily on reserve soldiers, the number of recruits who continue to serve in the reserves after completing mandatory service is important. In this study, 60 percent of both the males and females did reserve army service. This compares with more than 80 percent of regular infantry soldiers.

While this study indicates that women have successfully performed the role of light infantry soldiers in the IDF Karakal unit, the results should not be extrapolated to conclude that they would be similarly successful in a regular 
infantry unit. While infantry soldiers are expected to be able to carry equipment and supplies sufficient for several days of marching and combat 15-20 kilometers beyond enemy lines, light infantry are not. They are only expected to be able to march 4-5 kilometers with limited combat equipment. They perform most missions and patrols using vehicles. A further difference is the level of fitness. Only $48 \%$ of the females and $52 \%$ of the males in Karakal reached fitness levels at the end of basic training that would have allowed them to pass minimum IDF infantry soldier standards. The mean $\mathrm{VO}_{2}$ max of the females at the end of basic training $\left(36.8 \mathrm{~mL} \cdot \mathrm{kg}^{-1} \cdot \mathrm{min}^{-1}\right)$ was lower than the norm for females of their age with average fitness $\left(43 \mathrm{~mL} \cdot \mathrm{kg}^{-1} \cdot \mathrm{min}^{-1}\right)$ [27].

While some of the Karakal female soldiers could possibly be successful infantry soldiers, there are general inherent physical obstacles. Females have inherently only 70 percent of the lower body strength and 30-50 percent of the upper body strength of comparable sized males [28]. Also, because of hormonal differences, females doing strength training build less muscle bulk than males [29]. Identifying females who could successfully serve in IDF infantry units would require intensive screening and include physical fitness and exertion tests, similar to those required before admission to more elite IDF infantry units. This is especially necessary because while the female recruits in Karakal were volunteers for their unit, most of them did little prior physical activity to prepare themselves for the physical challenges of infantry service [27].

This paper has several limitations. The study compares the performance of females to that of males serving as light infantry soldiers. The study is observational and, therefore, the cohorts could not be matched in any way. The females in Karakal are volunteers to the unit while the males are assigned. The unit has high prestige for the females and low prestige for the males. This results in group bias but does not invalidate the group comparison which is between females and a male cohort who ordinarily serve in such a unit. It does not invalidate the study conclusion that the females perform at least as good as the males in the Karakal unit. Another study weakness is that because the data is pooled from several induction groups there may be variations in methods between groups. Additionally, not all tests were performed on all subjects. This is because, on any individual assessment day, soldiers may have been on limited duty or away from their unit on other assignments. The study supplemented data gathered by the orthopaedic surgeons in the field during basic training by computerized patient records. The active surveillance by the orthopaedists could have led to higher reported injury rates than those which are usually reported.

We conclude that, in general, female participation in the mixed gender light infantry Karakal unit is a success. Females are able to fulfill successfully the combat role of a light infantry soldier. Female soldiers in the unit have lower attrition rates than the males. The higher female incidence of overuse injuries and their lower physical fitness than the males throughout all stages of the Karakal training might represent an impediment to them performing the more arduous training and duties of regular infantry soldiers.

\section{Dedication}

The authors would like to dedicate this paper to the late Ms. Judith Misch, IDF medical informatics; without her assistance, this paper and many others could not have been completed. Her love of soldiers and data fueled her lifelong career in research to improve their health during their service.

\section{Conflict of Interests}

The authors declare that there is no conflict of interests regarding the publication of this paper.

\section{Acknowledgments}

The authors would like to thank the staff of the Heller Institute of Medical Research and the soldiers of Karakal for their cooperation. This study was supported in part by the US Department of Defense Bone Health and Military Medical Readiness Research Program (MRMC, no. W911QY08-P-0286). The opinions and assertions in this paper are those of the authors and do not necessarily represent official interpretation, policy, or views of the US Department of Defense or the Israel Defense Forces.

\section{References}

[1] N. S. Bell, T. W. Mangione, D. Hemenway, P. J. Amoroso, and B. H. Jones, "High injury rates among female Army trainees: a function of gender?" American Journal of Preventive Medicine, vol. 18, no. 3, pp. 141-146, 2000.

[2] A. Gam, L. Goldstein, Y. Karmon et al., "Comparison of stress fractures of male and female recruits during basic training in the Israeli anti-aircraft forces," Military Medicine, vol. 170, no. 8, pp. 710-712, 2005.

[3] B. H. Jones, M. W. Bovee, J. M. Harris III, and D. N. Cowan, "Intrinsic risk factors for exercise-related injuries among male and female army trainees," The American Journal of Sports Medicine, vol. 21, no. 5, pp. 705-710, 1993.

[4] J. Knapik, S. J. Montain, S. McGraw, T. Grier, M. Ely, and B. H. Jones, "Stress fracture risk factors in basic combat training," International Journal of Sports Medicine, vol. 33, no. 11, pp. 940946, 2012.

[5] M. J. Rauh, C. A. Macera, D. W. Trone, R. A. Shaffer, and S. K. Brodine, "Epidemiology of stress fracture and lower-extremity overuse injury in female recruits," Medicine \& Science in Sports \& Exercise, vol. 38, no. 9, pp. 1571-1577, 2006.

[6] L. M. Pollack, C. B. Boyer, K. Betsinger, and M. Shafer, "Predictors of one-year attrition in female Marine Corps recruits," Military Medicine, vol. 174, no. 4, pp. 382-391, 2009.

[7] J. Wolfe, K. Turner, M. Caulfield et al., "Gender and trauma as predictors of military attrition: a study of marine corps recruits," Military Medicine, vol. 170, no. 12, pp. 1037-1043, 2005.

[8] B. P. Bergman and S. A. S. J. Miller, "Equal opportunities, equal risks? Overuse injuries in female military recruits," Journal of Public Health Medicine, vol. 23, no. 1, pp. 35-39, 2001.

[9] J. J. Knapik, K. G. Hauret, J. L. Lange, and B. Jovag, "Retention in service of recruits assigned to the army physical fitness test enhancement program in basic combat training," Military Medicine, vol. 168, no. 6, pp. 490-492, 2003. 
[10] J. J. Knapik, S. Darakjy, K. G. Hauret et al., "Increasing the physical fitness of low-fit recruits before basic combat training: an evaluation of fitness, injuries, and training outcomes," Military Medicine, vol. 171, no. 1, pp. 45-54, 2006.

[11] W. E. Siri, "The gross composition of the body," Advances in Biological and Medical Physics, vol. 4, pp. 239-280, 1956.

[12] J. V. Durnin and M. M. Rahaman, "The assessment of the amount of fat in the human body from measurements of skinfold thickness," British Journal of Nutrition, vol. 21, no. 3, pp. 681-689, 1967.

[13] J. V. G. A. Durnin and J. Womersley, "Body fat assessed from total body density and its estimation from skinfold thickness: measurements on 481 men and women aged from 16 to 72 years," British Journal of Nutrition, vol. 32, no. 1, pp. 79-97, 1974.

[14] D. S. Moran, E. Israeli, R. K. Evans et al., "Prediction model for stress fracture in young female recruits during basic training," Medicine and Science in Sports and Exercise, vol. 40, no. 11, pp. S636-S644, 2008.

[15] N. Jones, Clinical Exercise Testing, WB Saunders, Philadelphia, $\mathrm{Pa}$, USA, 3rd edition, 1988.

[16] R. R. Pate, S. N. Blaire, J. L. Durstein et al., "Guidelines for exercise test administration," in ACSM's Guidelines for Exercise Testing and Prescription, pp. 55-89, Lea \& Febiger, Philadelphia, $\mathrm{Pa}$, USA, 4th edition, 1991.

[17] A. S. Finestone, A. Eldad, and C. Milgrom, "Pre-induction sport activity in prevention of stress fractures in elite infantry recruits," Harefuah, vol. 138, no. 9, pp. 719-722, 2000.

[18] A. Hadid, R. K. Evans, R. Yanovich, O. Luria, and D. S. Moran, "Motivation, cohesion, satisfaction, and their relation to stress fracture among female military recruits," European Journal of Applied Physiology, vol. 104, no. 2, pp. 329-335, 2008.

[19] S. L. Bem, "Gender schema theory: a cognitive account of sex typing," Psychological Review, vol. 88, no. 4, pp. 354-364, 1981.

[20] R. S. Lazarus, "Coping theory and research: past, present, and future," Psychosomatic Medicine, vol. 55, no. 3, pp. 234-247, 1993.

[21] S. C. Kobasa, "Commitment and coping in stress resistance among lawyers," Journal of Personality and Social Psychology, vol. 42, no. 4, pp. 707-717, 1982.

[22] S. C. Kobasa, S. R. Maddi, and S. Kahn, "Hardiness and health: a prospective study," Journal of Personality and Social Psychology, vol. 42, no. 1, pp. 168-177, 1982.

[23] S. Melamed, T. Kushnir, and A. Shirom, "Burnout and risk factors for cardiovascular diseases," Behavioral Medicine, vol. 18, no. 2, pp. 53-60, 1992.

[24] C. Milgrom, A. Finestone, N. Shlamkovitch et al., "Stress fracture treatment," Orthopaedics International Edition, vol. 3, pp. 363-367, 1995.

[25] S. T. Zwas, R. Elkanovitch, and G. Frank, "Interpretation and classification of bone scintigraphic findings in stress fractures," Journal of Nuclear Medicine, vol. 28, no. 4, pp. 452-457, 1987.

[26] N. Constantini, A. S. Finestone, N. Hod et al., "Equipment modification is associated with fewer stress fractures in female Israel border police recruits," Military Medicine, vol. 175, no. 10, pp. 799-804, 2010.

[27] E. Shvartz and R. C. Reibold, "Aerobic fitness norms for males and females aged 6 to 75 years: a review," Aviation Space and Environmental Medicine, vol. 61, no. 1, pp. 3-11, 1990.

[28] J. H. Wilmore, "The application of science to sport: physiological profiles of male and female athletes," Canadian Journal of Applied Sport Sciences, vol. 4, no. 2, pp. 103-115, 1979.
[29] C. H. Brown and J. H. Wilmore, "The effects of maximal resistance training on the strength and body composition of women athletes," Medicine \& Science in Sports \& Exercise, vol. 6, no. 3, pp. 174-177, 1974. 

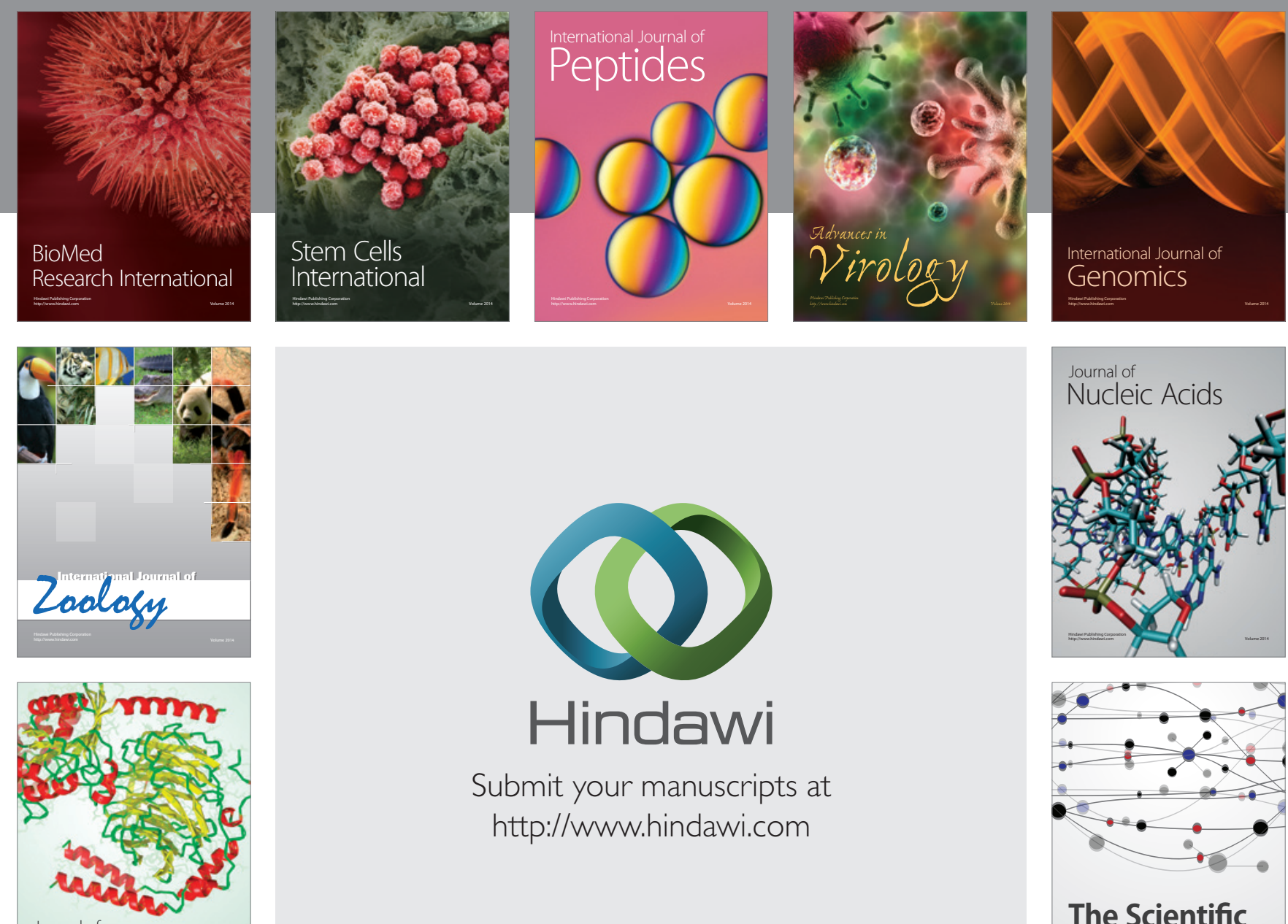

Submit your manuscripts at

http://www.hindawi.com

Journal of
Signal Transduction
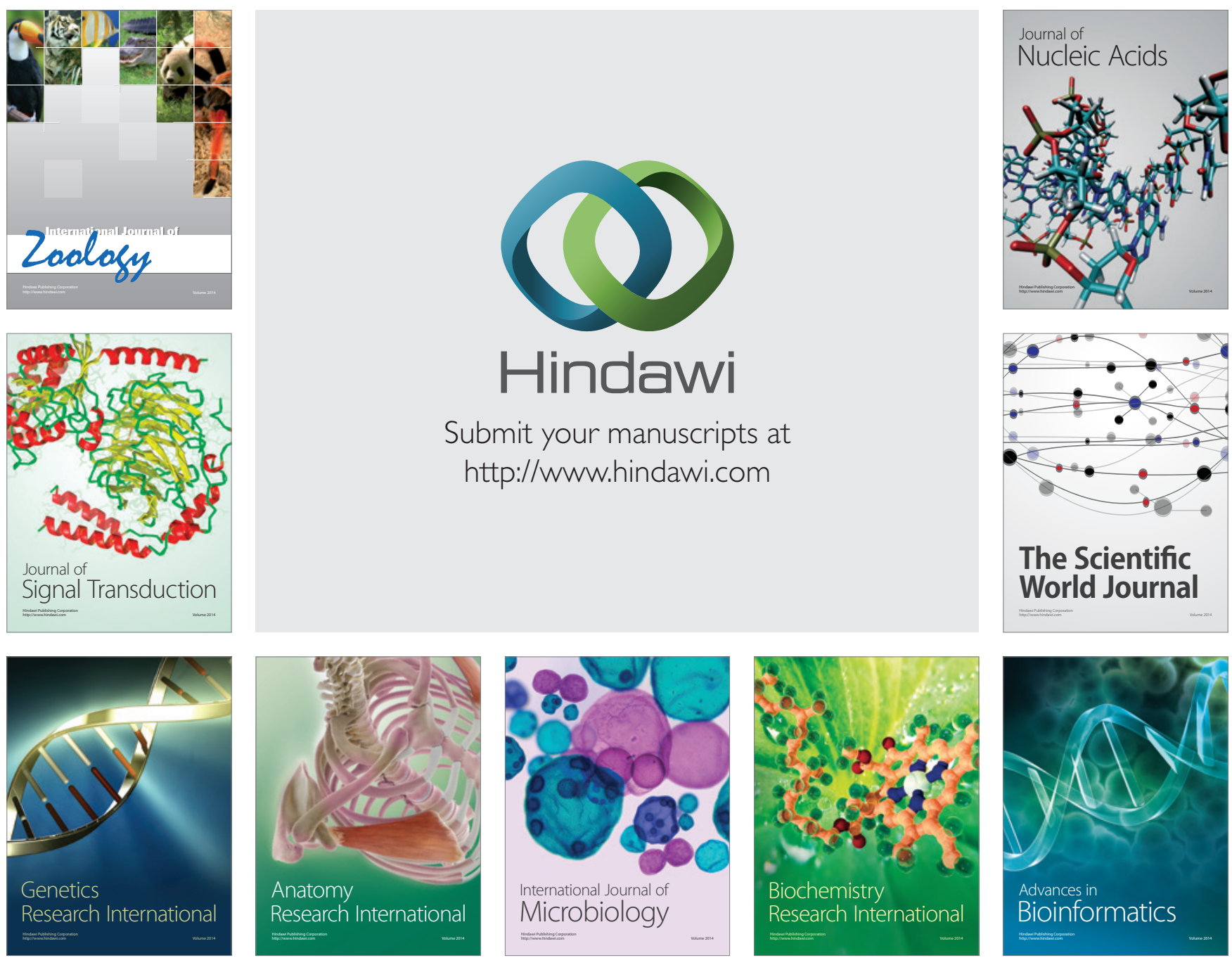

The Scientific World Journal
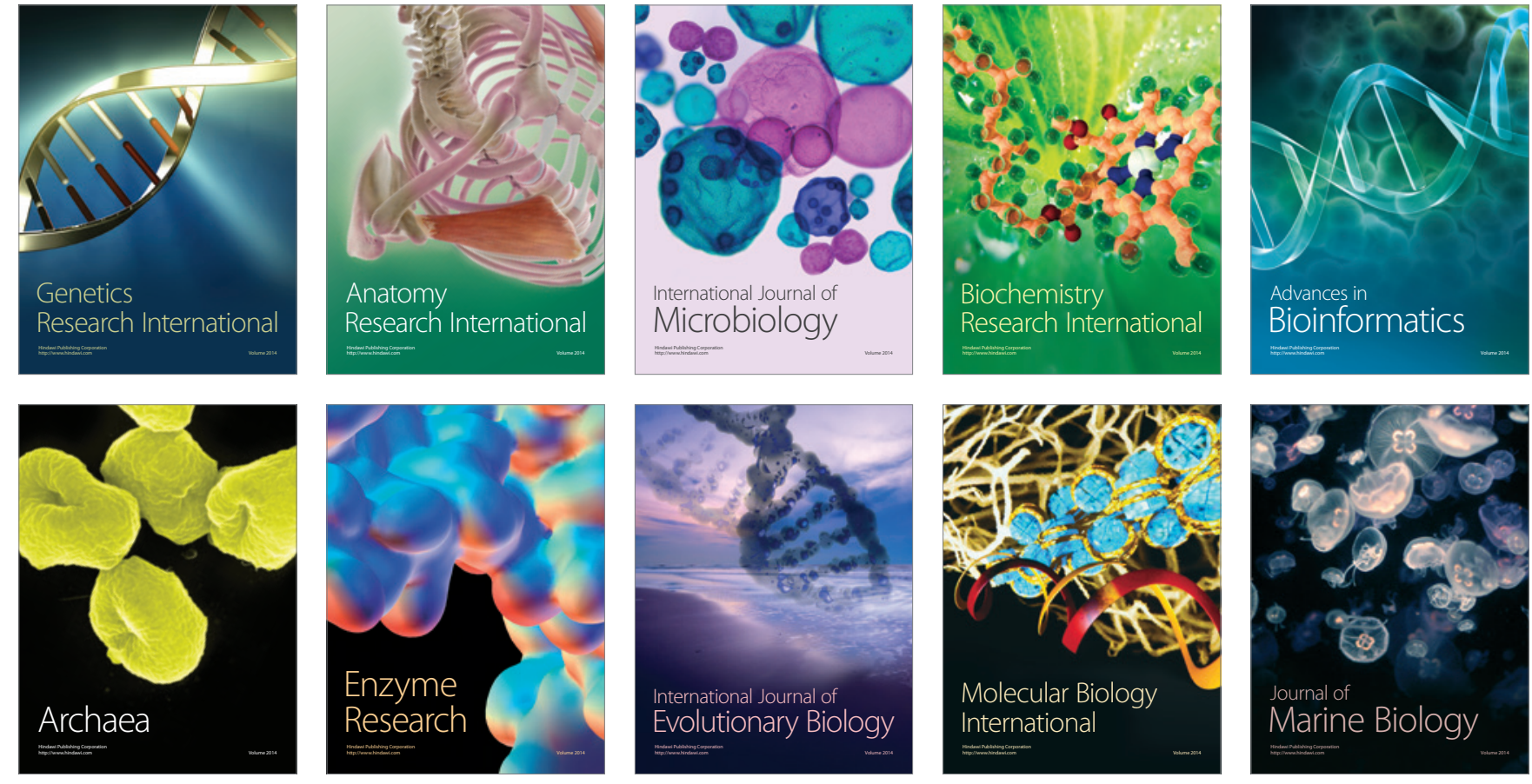